\title{
Prensa, política y orden social en Buenos Aires durante la década de 1850
}

\author{
Fabio WASSERMAN \\ Universidad de Buenos Aires \\ fwasserm@gmail.com
}

Recibido: 15 de diciembre de 2014

Aceptado: 4 de mayo de 2015

\section{Resumen}

El trabajo examina algunas reflexiones y discusiones sobre el rol y la naturaleza de la prensa que se produjeron en Buenos Aires durante la década de 1850 y que hacían referencia a las dificultades que implicaba congeniar la libertad y el orden. Esto se debía a que la prensa era considerada como un pilar de las sociedades republicanas y civilizadas, pero también como un agente capaz de corroer el orden social y político.

Palabras clave: Historia de la prensa; Opinión pública; Libertad de Imprenta; Buenos Aires; Década de 1850; Domingo F. Sarmiento.

\section{Press, politic, and social order in Buenos Aires during the 1850s}

\begin{abstract}
The paper examines some reflections and discussions about the role and nature of the press that took place in Buenos Aires during the 1850s, referring to the difficulties involved in congenial freedom and order. This was caused by the fact that the press was considered a pillar of republican and civilized societies, but also an agent capable of corroding the social and political order.
\end{abstract}

Key words: Press History; Public Opinion; Freedom of the Press; Buenos Aires; 1850s; Domingo F. Sarmiento.

\section{Referencia normalizada}

Wasserman, F. (2015). Prensa, política y orden social en Buenos Aires durante la década de 1850. Historia y Comunicación Social. Vol 20, número 1, páginas 173-187.

Sumario: 1. Introducción. 2. Prensa y política en Buenos Aires durante la década de 1850. 2.1. Prensa, opinión pública y libertad de imprenta. 2.2. Prensa y orden político. 3. Consideraciones finales. 4. Referencias bibliográficas.

\section{Introducción}

Existe una vasta tradición de estudios sobre la prensa hispanoamericana del siglo XIX que abarca desde trabajos sobre un medio, un redactor, un impresor, una imprenta, una temática o un período preciso, hasta obras de síntesis de alcance regio- 
nal, nacional o continental. En las últimas décadas se produjeron importantes cambios en este campo a partir del diálogo con otras subdisciplinas como la historia política, la historia cultural y la historia intelectual que permitieron formular nuevas líneas de indagación. En ese sentido se apunta a superar algunas aproximaciones tradicionales que, además de tener un carácter descriptivo, sólo consideraban a la prensa como un soporte de ideas, informaciones, representaciones o discursos. Por el contrario, y a pesar de recurrir a diversos enfoques, son varios los autores que la conciben como una práctica productora de sentido y/o como un actor social y político (Alonso, 2004; Glave, 2003; Jaksic, 2002; Palti, 2008; Ramos, 1989).

El presente trabajo, que se inscribe dentro de esta perspectiva, analiza una serie de reflexiones y discusiones sobre la naturaleza y el rol de la prensa que se produjeron en Buenos Aires durante la década de $1850^{1}$. El foco está puesto en las valoraciones que se hacían sobre su accionar y que estaban vinculadas con las tensiones provocadas por la necesidad de congeniar la libertad y el orden. La prensa era uno de los principales motivos de estas tensiones, pues si bien se la consideraba como un pilar de las sociedades civilizadas y de los regímenes representativos por su papel en la formación y representación de la opinión pública, también provocaba fuertes prevenciones por su capacidad para corroer el orden moral, social y político. De ahí que Domingo F. Sarmiento se permitiera sostener en forma descarnada que la prensa podía ser "reina o ramera" (El Nacional n 1350, 14-11-1856).

En verdad la tensión entre el orden y la libertad, así como las diversas valoraciones que se hacían sobre la prensa, no constituían una originalidad de la región ni eran para ese entonces una novedad. Se trataba de cuestiones que atravesaron la vida pública posrevolucionaria europea y americana y que en el caso rioplatense se pueden remontar hasta los inicios del proceso revolucionario e independentista en 1810 (Wasserman, 2012). Pero en la década de 1850 pasaron a un primer plano y se constituyeron en uno de los principales motivos de disputa en la provincia de Buenos Aires. Esto se debió, entre otras razones, al nuevo escenario público que se creó como consecuencia de los cambios políticos, sociales e institucionales producidos tras la disolución del régimen rosista a comienzos de 1852 (Lettieri, 2006; González Bernaldo, 2001; Halperín Donghi, 1982; Sabato, 2004; Wasserman, 2013). Uno de los actores centrales de esa renovada vida pública fue la prensa, pues en esos años se produjo un notable incremento en la cantidad de publicaciones que procuraban interpelar, modelar y representar a una opinión pública también en expansión (Auzá, 1978; Halperín Donghi, 1985; Román, 2003; Sabato, 2008). Los gobiernos, por su parte, si bien se declaraban liberales, aspiraban a tener un mayor control de los medios apelando a diversas estrategias de cooptación y de persecución, además de promover la sanción de normas para regular las publicaciones (Wasserman, 2009a). 


\section{Prensa y política en Buenos Aires durante la década de $\mathbf{1 8 5 0}$}

Desde un punto de vista político, la década de 1850 comenzó en la República Argentina el 3 de febrero de 1852 cuando se produjo la batalla de Caseros en la que un ejército integrado por fuerzas entrerrianas, correntinas, uruguayas y brasileras se impuso sobre las tropas que respondían a Juan Manuel de Rosas. La derrota motivó su exilio y el fin del régimen que en su calidad de Gobernador de Buenos Aires y máxima figura del partido federal había liderado durante más de veinte años. Al frente de la coalición vencedora se encontraba el Gobernador de Entre Ríos, Justo José de Urquiza, que se convirtió en el nuevo hombre fuerte de la política rioplatense por lo que pudo designar a Vicente López y Planes como el nuevo Gobernador de Buenos Aires. Sin embargo, su proyecto de unificar en un Estado nacional a las provincias que eran soberanas desde hacía décadas, encontró una férrea oposición en la dirigencia y en la población de Buenos Aires que además de oponerse a su liderazgo, no querían resignar el control sobre su aduana y su puerto. El 11 de septiembre de 1852 se produjo una revolución que logró la separación de la provincia y el desconocimiento de las autoridades nacionales. Las otras provincias se mantuvieron unidas y en mayo de 1853 sancionaron una Constitución que organizó a la República Argentina como un Estado federal presidido por Urquiza. Buenos Aires, por su parte, ratificó su autonomía y en abril de 1854 sancionó una Constitución plagada de ambigüedades en relación a su posible integración. La vida política de Buenos Aires estuvo signada en esos años por los enfrentamientos con el Estado federal. Pero también por las disputas por el acceso al poder entre quienes querían mantener la autonomía provincial a toda costa y quienes proponían utilizar sus recursos para encabezar la unificación nacional, sumándose hacia finales de la década quienes aspiraban a lograr ese desenlace mediante un acuerdo con las autoridades nacionales (Sabato, 2012; Scobie, 1964; Wasserman, 2013).

En ese marco conflictivo, y acompañando un sostenido crecimiento demográfico y económico, la escena pública provincial se renovó y enriqueció con la incorporación de nuevos actores, prácticas e instituciones. En marzo de 1852, el gobierno de López y Planes restauró la Ley de Imprenta sancionada en 1828. Además de sus consecuencias prácticas, se trataba de una medida que tenía una fuerte carga simbólica ya que expresaba una toma de distancia y una crítica hacia el régimen rosista que la había suspendido de hecho. La Ley consideraba responsables de las publicaciones a los editores o, en su defecto a los impresores, y estipulaba que serían considerados abusivos los impresos que atentaran contra la religión, promovieran la sedición, el desorden público, la desobediencia a las leyes o a las autoridades, fueran obscenos o inmorales, o atacaran la reputación de algún individuo. Asimismo establecía que los impresos que hicieran referencia al desempeño de los funcionarios no podían considerarse abusivos, aunque esta distinción entre lo público y lo privado no era fácil de establecer. En ese sentido resultaba decisivo el mecanismo para determinar la existencia de delito y la pena: un jurado de cinco ciudadanos debía dar lugar o no a la acusación, mientras que otro debía dictar sentencia, reduciendo la función de los 
jueces a ilustrarlo y a guardar el orden. Las penas podían ser multas, inhabilitación para garantir impresos y/o confinación temporal en un pueblo de la campaña.

Si bien la ley no fue respetada escrupulosamente por los gobiernos, esto no obstó para que se produjera un notable crecimiento de la prensa, tanto en lo que hace a la cantidad de publicaciones como a su progresiva diversificación temática ${ }^{2}$. Este crecimiento se vincula con la existencia de una opinión pública en expansión que procuraba ser interpelada, modelada y representada a través de la prensa, y que por eso mismo se constituyó en un actor central de la vida pública. En ese sentido fue decisivo su vínculo con la política, ya sea instalando temas y candidaturas, representando a una causa o a un sector, alentando la movilización de la población, apoyando o criticando al gobierno de turno. Este vínculo era además inevitable, pues la subsistencia de los medios dependía en buena medida del apoyo gubernamental o de alguna facción, ya sea a través de subsidios, provisión o arriendo de una imprenta, contratos para publicar documentos oficiales y, sobre todo, suscripciones.

\subsection{Prensa, opinión pública y libertad de imprenta}

La expansión de la prensa y su creciente importancia dieron lugar a numerosas reflexiones y polémicas en las que se ponía en cuestión su rol, así como también el alcance que debía tener la libertad de imprenta y la definición sobre qué era la opinión pública y cómo se la articulaba y representaba ${ }^{3}$. No es casual que las páginas de los diarios, periódicos y revistas se convirtieran en el principal medio donde se expresaban y se discutían estas cuestiones. Pero no sólo porque se trataba de su propia actividad, sino también porque al participar en estos debates, los medios y los periodistas podían ganar visibilidad, prestigio y legitimidad.

El $1^{\circ}$ de abril de 1852 se publicó en Buenos Aires el primer número de Los Debates. Su redactor principal era Bartolomé Mitre, quien años más tarde sería presidente de una Argentina unificada y sentaría las bases de su historiografía, pero que entonces era una figura poco conocida en su ciudad natal a la que había llegado dos meses antes como oficial del ejército de Urquiza tras haber pasado buena parte de su vida en el exilio. Es por eso que a modo de carta de presentación decidió publicar un editorial en el que se refería a los más diversos temas. Esa suerte de programa, al que tituló "Profesión de Fe", está encabezado por una extensa cita de Lamartine señalando que la gran pasión de la época es el porvenir y la perfectibilidad social cuyo instrumento es la prensa que "(...) ha cesado de ser un derecho político, y se ha convertido en una facultad, en un nuevo sentido, en una nueva fuerza orgánica del género humano, su única palanca para obrar sobre sí mismo". La decisión de Mitre de titular al diario como Los Debates, expresaba cuál debía ser a su juicio el rol de la prensa en esa nueva coyuntura: incitar y dar lugar a las discusiones como medio de informar, formar y orientar a la opinión pública y a los gobiernos. En ese sentido anticipaba que iba a ser un diario "(...) que llamará todas las opiniones a batirse en el terreno pacífico de la inteligencia y de la ley, llevando la luz del debate razonado sobre todas las cuestiones vitales que hoy se agiten, y tengan relación con los intereses generales del país". Asimismo advertía que el intercambio de opiniones era 
mucho más que un derecho pues “(...) la discusión es la primera garantía de orden de un pueblo" al actuar como una válvula reguladora de las pasiones que domestica los instintos y enseña a buscar la armonía o al menos a respetar a las mayorías. La prensa como medio en el que se discuten los intereses generales debía tener una función de pedagogía cívica y, por lo tanto, intervenía en el presente pero con la mira puesta en el futuro: “(...) así se preparará la discusión de la tribuna de las asambleas provinciales y del Congreso Nacional, y la discusión popular en los meetings y en los clubes que vendrán después" (Los Debates n 1, 1-4-1852).

Pocas semanas más tarde, el diario El Nacional que era dirigido por el político y jurista Dalmacio Vélez Sarsfield, publicó un artículo titulado "Diarismo" en el que proponía argumentos del mismo tenor ${ }^{4}$. Su autor, probablemente Palemón Huergo, explicaba que la prensa es una necesidad de primer orden en un pueblo civilizado, y que ésta presupone la libertad de imprenta y, por lo tanto, la libertad en general, marcando así un contraste con la época de Rosas. Pero no sólo consideraba que la prensa era imprescindible como defensora de las libertades públicas y agente de la civilización, sino también por su capacidad para expresar, informar y articular ideas e intereses sociales:

Los diarios son pues, una necesidad imperiosa de la nueva existencia que se desarrolla. Sin ellos sería imposible esa comunión de ideas, creencias, sentimientos y necesidades, que hace que un pueblo entero tenga conciencia de sí mismo, de sus derechos y deberes. Sin ellos, ¿cómo saber lo que este gran cuerpo social que se llama República Argentina quiere y piensa? Ellos son esos genios misteriosos que reproducen en mil ecos sonoros y penetrantes la más débil voz. Ellos son los guardianes de las libertades públicas; por eso la tiranía cuando quiere aniquilarlas, dirige primero sus tiros sobre esos generosos centinelas que velan incesantemente en su conservación. (El Nacional n ${ }^{\circ} 12,14-5-1852$ )

Asimismo advertía que si bien habían desaparecido las facciones que dividían al país, seguramente se iban a plantear distintas propuestas para constituir a la nación, por lo que la prensa tenía que asumir su rol como mediadora entre las diversas posiciones. Más aún, su deber era orientar y disciplinar a la opinión pública:

(...) la prensa periódica tiene forzosamente que tomar parte, y si es posible ponerse a la vanguardia de la opinión pública, para ilustrarla y morigerarla antes que su pensamiento se ponga en discusión en las asambleas legislativas; o cuanto menos correr a la par de estos cuerpos representativos, prestándoles el oportuno apoyo que ellos necesitan. (El Nacional ${ }^{\circ} 12,14-5-1852$ )

Los redactores de El Nacional y de Los Debates no eran los únicos en considerar que la caída de Rosas había inaugurado una nueva etapa en la que la prensa asumiría un rol constructivo orientando y representando a la opinión pública. Ahora bien, este pronóstico pronto comenzó a verse ensombrecido al ponerse sobre el tapete lo que podría considerarse como el lado oscuro de la prensa: su capacidad para cuestionar a las autoridades y, peor aún, para socavar el orden social, político y moral. Es por ello que se fueron haciendo cada vez más candentes los debates en torno al rol y a los 
límites que debía tener la prensa en una sociedad republicana y civilizada regida por principios liberales.

Esta cuestión comenzó a plantearse a los pocos días de restaurada la Ley de Imprenta, pues además de los periódicos comerciales, políticos y literarios, también comenzaron a editarse algunos de carácter satírico como La Avispa o El Padre Castañeta que aprovechaban la posibilidad de publicar anónimos para criticar a algunos funcionarios. Esto provocó numerosas reacciones como la del diario oficialista $E l$ Progreso que en una breve nota recordaba lo sucedido con la prensa en 1828 y en 1833, cuyo accionar licencioso y anárquico había contribuido a la llegada de Rosas al poder (El Progreso n ${ }^{\circ} 30,10-5-1852$ ). Frente a ese estado de cosas, proponía enmendar la Ley de Imprenta impidiendo la publicación de anónimos en materia de política u otra temática de interés público. Pero el gobierno de López y Planes se anticipó a este incipiente debate: el 12 de mayo desconoció la ley y ordenó la suspensión por diez días de cuatro periódicos satíricos, además de instruir al fiscal para que los acusara por atacar a la moral pública.

La suspensión despertó reacciones dispares, como el ya citado artículo de El Nacional que hacía una apología de la libertad y del papel que debía asumir la prensa. Mitre, por su parte, dio una respuesta principista al sostener que los males que acarreaba la libertad debían solucionarse con mayor libertad, mientras que proponía poner fin a los anónimos y eximir de responsabilidad a los redactores por los remitidos (Los Debates $\mathrm{n}^{\circ}$ 29, 11-5-1852). Pero para ese entonces ya no era sólo un escritor público: un mes antes había sido electo legislador provincial. Y en esa calidad presentó un proyecto de ley con más de noventa artículos "Sobre uso y abuso de la libertad de imprenta" (Los Debates $\mathrm{n}^{\circ} 35$ y 36,18 y 19-5-1852). Procurando justificar la contradicción entre ese proyecto tan minucioso y su apología de una libertad absoluta, sostuvo una suerte de desdoblamiento de su persona al plantear que en esas circunstancias actuaba como legislador y no como filósofo.

La duplicidad de Mitre no pasó desapercibida y le valió ataques en dos frentes que ponían de manifiesto la dificultad que entrañaba encontrar un equilibrio entre la libertad y el orden tal como pretendía. Semanas más tarde, una reaparecida La Avispa publicaba un remitido firmado por "Un imbécil" que se preguntaba si el redactor de Los Debates "es Dios, es Gobierno o es legislatura" para dictar leyes, mandatos o decretos, alegando que no habría por qué poner condiciones para publicar comunicados sin firma (La Avispa $\mathrm{n}^{\circ} 56,21-6-1852$ ). El otro flanco fue atacado por el diario oficialista que emitió una dura crítica de su posición en pro de una libertad irrestricta, alegando que

Nosotros creemos firmemente que si los principios semiprogresistas, semianárquicos de Los Debates triunfan, y todo puede ser en un pueblo nuevo como el nuestro, todo se convertirá en debates en esta tierra desgraciada: debates con la pluma, debates con la lanza y debates con el puñal (El Progreso n $\left.{ }^{\circ} 37,18-5-1852\right)$.

¿Los debates en la prensa contribuían a consolidar el orden social y político o lo ponían en peligro? El redactor de El Progreso temía esta última posibilidad, por lo 
que ponía en duda que todo pudiera ser motivo de discusión, máxime si se tenía en cuenta que en esas circunstancias el trecho que separaba a la pluma del puñal no era difícil de recorrer.

No era el único en considerar que esto podía suceder, tal como lo dejó en claro al año siguiente Juan B. Alberdi en la agria polémica que tuvo con Sarmiento. Si bien esta discusión entre los dos publicistas más renombrados de Argentina se produjo en Chile, lo que estaba en discusión era el rol que debía tener la prensa de su país, tal como lo hizo explícito Alberdi al titular su primera intervención como Cartas sobre la prensa y la política militante en la República Argentina. Por eso afirmaba que "Hablar de la prensa es hablar de la política, del gobierno, de la vida misma de la República Argentina, pues la prensa es su expresión, su agente, su órgano" (Alberdi, 2005: 41). Sarmiento también compartía esa apreciación, y probablemente éste haya sido uno de los pocos motivos de acuerdo entre ambos, cuyas disputas estuvieron atravesadas por enconos personales y diferencias políticas e ideológicas, pero sobre todo por la ruptura entre Buenos Aires y Urquiza que los encontró en bandos enfrentados.

Alberdi argüía que los periodistas formados en la lucha contra Rosas no debían tener cabida en esa nueva coyuntura que demandaba escritos constructivos y capaces de orientar el progreso socioeconómico. Esto implicaba un cambio en los contenidos, pero también en el tono y en el estilo, pues la discusión ya no era entre enemigos irreconciliables, por lo que debía dejarse de lado el insulto, la agresión, la mentira y la exageración que había caracterizado a la prensa en esos años. Sin embargo, según advertía, la prolongada lucha contra Rosas había forjado un estilo periodístico belicoso que no sería fácil de desarraigar. En ese sentido, y en clara alusión a Sarmiento, lamentaba que la prensa también tuviera sus "caudillos" y sus "gauchos malos" que predicaban la civilización pero actuaban como bárbaros, convirtiéndose así en aquello que habían combatido durante años e impidiendo la consolidación de un nuevo orden:

Defiende las garantías privadas contra los ataques del sable, pero olvida que el hogar puede ser violado por la pluma. Estigmatiza al gaucho que hace maneas con la piel del hombre, y él saca el pellejo a su rival político con pretexto de criticarlo (...) Si los gauchos en el gobierno son obstáculos para la organización de estos países, ¿los gauchos de la prensa podrán ser auxiliares y agentes del orden y del gobierno regular? (Alberdi, 2005: 51).

Esta polémica gozó de una amplia difusión en Hispanoamérica. No sólo por la importancia de sus protagonistas y las ofensas que se dispensaron para deleite de sus admiradores y detractores, sino también por los argumentos que esgrimían y que serían invocados en las más diversas circunstancias.

\subsection{Prensa y orden político}

En Buenos Aires, la discusión sobre la prensa que también se nutrió de los debates producidos en Europa, Estados Unidos u otros países de Hispanoamérica, se entre- 
lazó con el principal problema político suscitado en esos años: la disputa por el lugar que debía tener la provincia en el orden político nacional. Es por ello que si bien podía expresarse casi cualquier idea o posición, incluso en términos descomedidos, lo que no podía hacerse era pronunciarse en favor de Rosas o de Urquiza, criticar a la revolución del 11 de septiembre o impugnar a la Constitución provincial. Se trataba de un límite casi infranqueable que dibujaba un contorno preciso sobre qué era legítimo y qué era ilegítimo.

En ese marco fueron perseguidos los medios sospechados por su connivencia con Urquiza, como la Ilustración Argentina que fue clausurada en marzo de 1854 mientras se terminaba de debatir la Constitución provincial. En los años siguientes se produjeron otros hechos similares, casi siempre en circunstancias en las que aumentaban las tensiones con el Estado nacional y se producían hechos de violencia en la frontera o en la campaña. Pero esto no era todo, pues también hubo entredichos con medios que si bien acordaban con el rumbo adoptado por la provincia, no apoyaban al ejecutivo provincial en forma irrestricta. Estos conflictos fueron recurrentes durante el mandato de Pastor Obligado (1853-1857), cuyo Ministro de Gobierno, Ireneo Portela que ejerció el cargo hasta 1855, era tildado como lento e irresuelto. Es por eso que se produjeron diversos intentos del ejecutivo para controlar a la prensa a través de juicios que solían quedar en la nada, por lo que recurrió a otros medios como el desalojo de las oficinas del diario La Tribuna en junio de 1855, o la cooptación mediante la suscripción de ejemplares o la contratación para publicar documentos oficiales.

Ese estado de cosas, sumado a las alusiones cotidianas sobre figuras públicas que se hacían en libelos, en remitidos anónimos o en secciones de los periódicos como "Crónica local" o "Hechos locales", hizo inevitable que se produjeran polémicas referidas al rol de la prensa y a la necesidad de sancionar una nueva normativa que la regulara. Esta posibilidad era en general rechazada de plano por los principales periódicos, tal como lo hizo Héctor Varela desde las páginas de La Tribuna en un artículo que tituló "La libertad en la Prensa, es el agente civilizador de el mundo". (La Tribuna $\mathrm{n}^{\circ} 126,11-1-1854$ )

Ese título, que constituía un verdadero cliché, era seguido por un epígrafe con una cita de Alexis de Tocqueville señalando que "(...) la prensa es ese poder extraordinario en el que existe una mezcla singular de bienes y de males, sin los cuales no podría vivir la libertad, y que con ellos apenas se consigue mantener el orden" ( $L a$ Tribuna $\mathrm{n}^{\circ} 126,11-1-1854$. Destacado en el original). De ese modo, y más allá de cuál pudo haber sido su intención, Varela ponía en evidencia la naturaleza ambigua de la prensa, esa "mezcla singular de bienes y de males", cuyos abusos por eso mismo ya no podían seguir atribuyéndose únicamente al accionar de periodistas inescrupulosos o a rémoras de las luchas civiles destinadas a desaparecer.

Las reflexiones más agudas en ese sentido fueron obra de Sarmiento, quien a mediados de 1855 regresó de Chile y asumió la redacción de El Nacional. En agosto de ese año sumó su voz a la de quienes criticaban un nuevo intento del ejecutivo de sancionar una norma limitando los posibles abusos de la prensa. Para el autor 
de Facundo se trataba de un problema sin solución y no una herencia del rosismo destinada desaparecer como muchos preferían creer. Por eso alegaba que "(...) toda la ciencia de Europa no ha encontrado el secreto que estamos buscando nosotros ahora", entre otras razones, porque si bien resultaba fácil poner en un papel "Ataques contra la moral, contra la religión del Estado, contra la tranquilidad pública", no sucedía lo mismo cuando debía determinarse ese abuso en los hechos. En cuanto a qué debía hacerse, consideraba que hasta el momento se habían tomado dos caminos: el de Estados Unidos e Inglaterra que no dictaron leyes específicas y dejaron que sus excesos fueran juzgados por las leyes comunes; y el de Francia, cuyas leyes de imprenta inspiraron a los países de Hispanoamérica, y cuyo propósito había sido disfrutar del bien y apartar el mal que acarreaba la prensa, habiendo fracasado a su juicio en ambos cometidos. Es por eso que hacía profesión de fe liberal confiando en que el propio uso de la libertad pudiera enseñar a moderarse a sí misma (El Nacional no 987 18-8-1855). Un año más tarde tuvo la oportunidad de reafirmar esta posición cuando fue blanco de una campaña de difamación personal. En respuesta a estos artículos que fueron la comidilla de la sociedad, escribió un artículo en el que se quejaba de los excesos cometidos por quienes consideraba herederos de la prensa rosista, proponiendo sin embargo que "Haya libertad para todos" (El Nacional no 1350, 14-11-1856).

Más allá de las cuestiones personales, que en el caso de Sarmiento eran inevitables, estos ataques se produjeron en un contexto en el que recrudecían los enfrentamientos entre diversas facciones, provocando nuevos alineamientos y planteándose en algunos casos la posibilidad de llegar a algún acuerdo con Urquiza. A mediados de 1857 asumió la gobernación Valentín Alsina que lideraba el ala más intransigente de la dirigencia de Buenos Aires, dando por tierra con cualquier iniciativa en ese sentido. La prensa opositora, liderada por La Reforma Pacifica de Nicolás Calvo, atacaba cotidianamente a las principales figuras y medidas del oficialismo. Para poner freno a estos ataques, el gobierno ideó un mecanismo ingenioso que le permitía controlar a los medios sin transgredir los principios liberales. En septiembre de 1857 se sancionó una nueva norma cuya única innovación fue la supresión de los jurados para tratar los casos de particulares afectados por injurias, calumnias o difamaciones, cuyas causas pasarían a ser juzgadas y sancionadas por la justicia civil o criminal según correspondiera. Si bien se trataba de un cambio procedimental, no era para nada inocuo. Por un lado, porque los jueces eran mucho más permeables a las presiones del gobierno que los jurados de ciudadanos que en muchas ocasiones ni siquiera lograban constituirse. Por el otro, porque precisar cuándo se estaba ante un agravio personal y cuándo ante una crítica a la actuación pública, era un acto que se prestaba a la discrecionalidad.

En esta ocasión, y al igual que lo había hecho Mitre un lustro antes, Sarmiento también se permitió desdoblar su personalidad. Si bien en el Senado apoyó la ley, también planteó sus dudas al insistir en que "Conciliar, pues, esta necesidad absoluta de libertad sin límites de la prensa, con la quietud de las familias, con el reposo de los ciudadanos, es el problema hasta hoy día insoluble en todas partes". Por eso concluía que "La prensa es la cosa más bella y más horrible, como lo sienten todos en Buenos Aires y también los que escriben" (Sarmiento, 1948: p. 94 y 96). Pero esto no era 
todo: además de legislador y filósofo (o más bien publicista) Sarmiento, al igual que Mitre, también era un político. Unas pocas semanas más tarde se congratuló por la sanción de la nueva ley, precisando que sería utilizada contra La Reforma Pacifica “(...) que tendrá pronto diez procesos criminales y seguramente sus redactores diez condenaciones que sufrir en la cárcel pública o por penas pecuniarias" (El Nacional $\left.\mathrm{n}^{\circ} 1611,16-10-1857\right)$. No se trataba de una bravuconada ni de una mera expresión de deseos. En marzo de 1858, y tras haber perdido varios juicios, cerró La Prensa, el único medio urquicista que llegó a publicarse en Buenos Aires. La Reforma Pacífica, por su parte, si bien tenía mayor arraigo y contaba con apoyos en la provincia, tampoco pudo resistir la acumulación de multas, por lo que dejó de publicarse en 1859 mientras que sus redactores y editores padecían la cárcel y el destierro.

Para ese entonces las disputas entre Buenos Aires y el Estado nacional habían llegado a un punto cuya única resolución posible parecía ser el enfrentamiento armado, tal como sucedió el 23 de octubre de 1859 cuando un ejército comandado por Urquiza se impuso en la batalla de Cepeda sobre las fuerzas de Buenos Aires dirigidas por Mitre. Tras la renuncia de Alsina a la gobernación, se firmó un Pacto de Unión y Paz acordando la incorporación de la provincia a la nación. Para ello se convocaba a una convención provincial que podía proponer reformas a la constitución de 1853, tal como se verificó al año siguiente. De ese modo se daba cierre a la década de 1850, pero no a los conflictos referidos a la organización nacional que se prolongarían dos décadas más plagadas de conflictos internos y externos en los que la prensa y los debates sobre su rol y los límites de la libertad de imprenta, seguirían teniendo un lugar central.

La persecución judicial, política, económica e incluso física que sufrían los medios y los periodistas o editores opositores, permitiría calificar como hipócritas a quienes desde el oficialismo invocaban a la libertad de imprenta. Y de hecho es lo que hizo Calvo al sancionarse la reforma de 1857, ocasión en la que acusó a Mitre y Sarmiento de ser "demócratas para subir y aristócratas para conservar" (La Reforma Pacifica $\mathrm{n}^{\mathrm{o}}$ 229, 17-9-1857), precisando al día siguiente que eran "Tribunos de ayer, gobernantes de hoy, tiranos del porvenir" (La Reforma Pacifica n 230, 18-9-1857).

La hipocresía puede ser cierta en algunos casos. Pero éste es tan sólo un aspecto del problema y no necesariamente el más relevante. Es que si nos contentáramos con reducirlo a un juicio moral, podría perderse de vista una cuestión mucho más significativa y que afectaba los fundamentos del orden político republicano y liberal. Como pudo apreciarse, frente a los embates promovidos por la prensa opositora o tan sólo crítica de ciertas medidas, los gobiernos procuraban diseñar mecanismos que permitieran articular la libertad y el orden. Pero se trataba de un equilibrio precario e inestable que requería de constantes reajustes, vale decir, de la acción política atenta a los intereses y a las relaciones de fuerza coyunturales. De ese modo, la sospecha de que se trataba de un propósito imposible de alcanzar, para algunos se iba convirtiendo en una certeza. 
Las consideraciones que se hacían en ese sentido podían ser diversas, dependiendo tanto, de las convicciones y los encuadramientos políticos, como de la sensibilidad y el temple de quiénes las sostuvieran. Mitre por ejemplo, que solía mostrarse optimista incluso en las situaciones más adversas, advertía que

El desarrollo de la industria tipográfica y el movimiento del diarismo, son dos síntomas que revelan el progreso que ha hecho la inteligencia entre nosotros, después de la caída de la tiranía. La inteligencia se ha emancipado y ha tomado vuelo para caer como Ícaro algunas veces, para extraviarse otras, pero siempre avanzando, siempre progresando (Los Debates n ${ }^{\circ} 60,30-7-1857$ ).

Quienes se identificaban con posiciones más conservadoras como los editores del diario El Orden, no temían asumir que la libertad de imprenta era un bien que debía ser regulado para proteger valores más trascendentes. Algunos incluso se permitían dudar si la prensa era el medio más adecuado para tratar temas tan delicados como la organización nacional, poniendo así en cuestión la relación entre prensa y opinión pública sobre la cual hasta ese entonces parecía haber un extendido consenso. En septiembre de 1857, y a pocos días de sancionada la reforma de la Ley de Imprenta, el periódico La Religión publicó un artículo sobre este tema titulado "La cuestión nacional". Pero antes de plantear las posibles alternativas que se le presentaban a la provincia y cuál era el camino que le convenía transitar, el autor consideró necesario interrogarse por el rol que debían asumir los medios que expresaban y formaban a la opinión pública:

(...) no sabemos si es más conveniente hablar que callar, y si no es preferible el silencio a ese tono destemplado del odio, usado casi siempre que se trata este negocio, que más que ningún otro reclama el lenguaje de la moderación y de la prudencia (...) no son los artículos de la prensa ni los discursos del orador en las cámaras los que han de colocar en buena vía esta cuestión, entendida y practicada la discusión tal como se entiende y practica entre nosotros. (...) La prensa y la tribuna con sus pasiones y sus escándalos no harían más que alejar la hora deseada de la reconciliación (La Religión año V n ${ }^{\circ}$ 7, 26-9-57).

En esta misma línea, el político y publicista salteño Facundo Zuviría había publicado poco tiempo antes un exhaustivo trabajo titulado La prensa periódica en el que proponía regular con urgencia la libertad de imprenta antes que sus efectos nocivos terminaran de corroer la moral pública y el orden social. Sus observaciones eran tan puntillosas como repetitivas, lamentando por ejemplo que los abusos no fueran hechos en nombre de sus autores "(...) sino a nombre de la opinión pública de que se llaman sus órganos legítimos y exclusivos. ¡Lamentable uso de las ideas y de las palabras!", para reafirmar pocas líneas después su crítica al descalificar a esos "obscuros periodistas" que se arrogaban ser "Órganos de la pública opinión" (Zuviría, 1857: p. 39-40. El destacado en el original). Lo más interesante de esta diatriba es que a pesar de no tener duda alguna en la necesidad de regular a la prensa, y de ofrecer propuestas minuciosas para cumplir con ese cometido, Zuviría también dejó entrever que no se trataba de un problema que pudiera resolverse sin afectar los fundamentos del orden político vigente y a los que él también adhería: 
La prensa periódica gemela con nuestras pobres instituciones, tampoco ha dejado arraigarlas, sino que desde su nacimiento las ha debilitado o destruido con sus incansables ataques. Ha sido para ellas como una serpiente criada en su cuna, o como una enfermedad en la infancia, que no permite o vicia el desarrollo físico de los cuerpos orgánicos (Zuviría, 1857: p. 27. El destacado en el original)

De ese modo reconocía a su pesar que los males de la prensa no se debían tanto al uso indebido que algunos hacían de ese preciado bien, sino que se trataba de un fenómeno inherente al propio desarrollo social y político y, por lo tanto, imposible de erradicar. Claro que aunque atisbara esa posibilidad, Zuviría nunca se permitió arribar a esa conclusión.

Quien sí asumió esa posibilidad fue Sarmiento cuando se preguntaba si era posible regular la libertad de imprenta sin desnaturalizarla. Ante ese callejón sin salida creía preferible correr el riesgo que entrañaba apostar por la libertad. Es por ello que dedicó un artículo a criticar el libro de Zuviría, al que consideraba tan minucioso como irrelevante. Asimismo reafirmaba que la prensa era una expresión inequívoca de progreso, destacando que estaban discutiendo sobre un medio cuya existencia era inherente al orden social y político:

Prensa periódica, quiere decir, en derecho, la facultad de hablar en público, todos los días, para formar la opinión de los lectores sobre el gobierno, las leyes, los hombres públicos, las ideas, la política, los partidos, de omni re scibili y también como agregaba maliciosamente Voltaire: et de quibusdam aliis.

Esta facultad no emana de la prensa sino de la organización de las sociedades modernas, en que cualquiera tiene derecho de influir en la marcha de los poderes públicos y donde nadie tiene el privilegio de conocer la verdad, ni de no errar ( $E l$ Nacional $\mathrm{n}^{\mathrm{o}} 1608$ y 160913 y $14-10-1857$ )

Para Sarmiento la prensa era un actor central en una república representativa y en una sociedad moderna y civilizada, por lo que decía no estar dispuesto a coartarla a pesar de los males que pudieran acarrear sus excesos que asumía como algo inevitable e inherente a su naturaleza. $\mathrm{O}$ al menos esa era su posición cuando debía enfrentar a quienes proponían restringir la libertad de imprenta, cuyas consecuencias creía imprevisibles:

En esto está la gravedad de la cuestión de libertad de imprenta. No hay juez humano que pueda distinguir lo que es libertad, de lo que es licencia, sin temor que él llame licencia a la libertad misma, ni menos separe la demagogia del patriotismo" (El Nacional n $\mathrm{n}^{\mathrm{o}} 1608$ y 160913 y 14-10-1857).

\section{Consideraciones finales}

No era la primera vez que Sarmiento rechazaba la posibilidad de regular la libertad de imprenta con leyes especiales. Ya lo había hecho el año anterior cuando había sido víctima de ataques personales, ocasión en la que también se permitió redefinir de un 
modo singular el tópico de la opinión pública como reina del mundo: “(...) déjese a la prensa, esta reina o ramera, según quien la inspira, entregarse a sus propios instintos. Una sola palabra suya puede salvarnos de males más duraderos que los rasguños que hace diariamente a las más esclarecidas reputaciones" (El Nacional n ${ }^{\circ} 1350,14-11$ 1856). De ese modo daba cuenta de la doble cara de la prensa que tanto podía apuntalar como socavar el orden y la moral pública. Pero bien podría plantearse que no se trataba de una disyunción, pues el problema radicaba precisamente en el hecho que, al igual que en su reconocido Facundo cuyo subtítulo era Civilización y Barbarie, la prensa era a la vez reina y ramera. Es por eso que en otras ocasiones fue más preciso al considerarla como "la cosa más bella y la más horrible", y a la libertad de imprenta como "ese monstruo que es ángel tutelar y demonio instigador a la vez" (El Nacional $\mathrm{n}^{\mathrm{o}}$ 987, 18-8-1855).

De ese modo Sarmiento asumía que estaban condenados a vivir en una sociedad en la que la libertad, ese preciado bien traído medio siglo antes por la revolución republicana, también hacía imposible la consolidación de todo orden. Ningún juez humano podía distinguir con certeza la libertad de la licencia. De ese modo, los excesos o abusos sólo podían tener una respuesta parcial y política que debía suturar en forma precaria y contingente las brechas provocadas por la prensa, ese monstruo de dos caras con el que estaban condenados a vivir y a lidiar si querían seguir gozando de la libertad.

\section{Referencias bibliográficas}

4.1. Colecciones de periódicos (se indican los años consultados)

La Avispa. Palo ciego al que no ande derecho (1852). Buenos Aires: Imprenta Republicana e Imprenta de Arzac.

Los Debates. Diario de intereses generales. Política. Comercio. Literatura (1852). Buenos Aires: Imprenta Americana.

Los Debates. Diario de intereses generales (1857/8). Buenos Aires: Imprenta Argentina, 2da época.

El Nacional. Periódico comercial, político y literario (1852/9). Buenos Aires: Imprenta Argentina.

El Padre Castañeta, Periódico Crítico-Burlezco (sic) literario, Político y de Costumbres (1852). Buenos Aires: Imprenta de Arzac.

El Progreso. Diario Gubernativo (1852). Buenos Aires: Imprenta del Estado.

La Reforma Pacifica. Diario Político, Literario y Mercantil (1856/9). Buenos Aires:

Imprenta de la Revista e Imprenta de la Reforma Pacifica.

La Religión (1857). Buenos Aires, Imprenta de Mayo.

La Tribuna (1853/9). Buenos Aires: Imprenta de La Tribuna. 


\subsection{Bibliografía}

ALBERDI, J. B. (2005). "Cartas sobre la prensa y la política militante en la República Argentina”. En Pagliai, L. (ed.) La gran polémica nacional, Buenos Aires: Leviatán. p. 35-139.

ALONSO, P. (comp.) (2004). Construcciones impresas. Panfletos, diarios y revistas en la formación de los Estados nacionales en América Latina, 1820-1920. Buenos Aires: Fondo de Cultura Económica.

AUZÁ, N. (1978). El Periodismo de la Confederación (1852-1861). Buenos Aires: Eudeba.

GLAVE, L. (2003). "Del pliego al periódico. Prensa, espacios públicos y construcción nacional en Iberoamérica". En Debates y perspectivas. Cuadernos de Historia y Ciencias Sociales $\mathrm{n}^{\mathrm{o}}$ 3. Madrid: Fundación Mapfre Tavera.

GOLDMAN, N (2008). "Opinión Pública”. En Goldman, N. (ed.). Lenguaje y revolución. Conceptos políticos clave en el Río de la Plata, 1780-1850. Buenos Aires: Prometeo. p. 99-113.

GONZÁLEZ BERNALDO, P. (2001). Civilidad y politica en los orígenes de la Nación Argentina. Las sociabilidades en Buenos Aires, 1829-1862. Buenos Aires: Fondo de Cultura Económica.

HALPERÍN DONGHI, T. (1982). Una nación para el desierto argentino. Buenos Aires: Ceal.

(1985). José Hernández y sus mundos. Buenos Aires: Sudamericana.

JAKSIC, I. (comp.) (2002). The Political Power of the Word. Press and Oratory in Nineteenth-Century Latin America. Londres: Institute of Latin American Studies.

LETTIERI, A. (2006). La construcción de la República de la opinión. Buenos Aires frente al interior en la década de 1850. Buenos Aires: Prometeo, 2006.

MOLINA, E. (2009). El poder de la opinión pública. Tensiones y avatares de una nueva cultura política en el Río de la Plata, 1800-1852. Santa Fe: Universidad Nacional del Litoral.

MYERS, J. (2003). "Las paradojas de la opinión. El discurso político rivadaviano y sus dos polos: el gobierno de las luces y la opinión pública, reina del mundo". En Sabato, H y Lettieri, A. (eds.). La vida política en la Argentina del siglo XIX. Armas, votos y voces, Buenos Aires: Fondo de Cultura Económica. p. 75-95

PALTI, E. (2008). La invención de una legitimidad. Razón y retórica en el pensamiento mexicano del siglo XIX (un estudio sobre las formas del pensamiento politico). Buenos Aires: Fondo de Cultura Económica.

(2009). El momento romántico. Nación, historia y lenguajes políticos en la Argentina del siglo XIX. Buenos Aires: Eudeba.

RAMOS, J. (1989). Desencuentros de la modernidad en América Latina. Política y literatura en el siglo XIX. México: Fondo de Cultura Económica.

ROMÁN, C. (2003). "La prensa periódica. De La Moda (1837-1838) a La Patria Argentina (1879-1885)". En Schvartzman, J. (dir.) La lucha de los lenguajes, Historia crítica de la literatura argentina t. II. Buenos Aires: Emecé. p. 439-467.

SABATO, H. (2004). La politica en las calles. Entre el voto y la movilización, Buenos Aires, 1862-1880. Bernal: Universidad Nacional de Quilmes. 
(2012). Historia de la Argentina, 1852-1890. Buenos Aires: Siglo XXI.

SARMIENTO, D. F. (1948). Obras Completas t. 18. Buenos Aires: Luz del Día.

SCOBIE, J. (1964). La lucha por la consolidación de la nacionalidad argentina, 1852-1862-Buenos Aires: Hachette.

WASSERMAN, F. (2009a). "La libertad de imprenta y sus límites: prensa y poder político en el Estado de Buenos Aires durante la década de 1850". En Almanack Braziliense $n^{\circ} 10$, San Pablo (Brasil), p. 130-146.

(2009b). "Notas sobre el diarismo en la prensa porteña de la década de 1850". En Muñoz, M. y Vermeren, P. (comps.). Repensando el siglo XIX desde América Latina y Francia. Homenaje al filósofo Arturo A. Roig. Buenos Aires: Editorial Colihue. p. 257-264.

(2012). "Entre la moral y la política. Las transformaciones conceptuales de liberal en el Río de la Plata (1780-1850)". En Fernández Sebastián, J. (coord.). La aurora de la libertad. Los primeros liberalismos en el mundo iberoamericano. Madrid: Marcial Pons. p. 37-73

(2013). "La conflictiva vida política: entre el orden local y la organización nacional”. En Ternavasio, M. (dir.). De la organización provincial a la federalización de Buenos Aires (1821-1880), Colección Historia de la Provincia de Buenos Aires, t. III, Buenos Aires: Edhasa. p. 153-177.

ZUVIRÍA, F. (1857). La prensa periódica. Montevideo: Imprenta de la República.

\section{Notas}

1 El texto forma parte de una investigación en curso sobre "Prensa y vida pública en Buenos Aires durante la década de 1850". Una versión preliminar fue discutida en el Segundo Encuentro Regional Noticias de los medios (1880-1960) realizado en la Biblioteca Nacional, Buenos Aires, 14 y 15 de julio de 2014. Le agradezco a Mariano Aramburo por su colaboración en la recolección de la información.

2 Entre 1852 y 1860 se publicaron decenas de medios con diversas tiradas. Si bien muchos fueron efímeros, hubo algunos que salieron regularmente como los diarios La Tribuna y El Nacional, mientras que otros lo hicieron durante un lapso prolongado como Los Debates, La Crónica, El Orden o La Reforma Pacifica. Además de estos impresos que eran de carácter político y económico, y de las tradicionales publicaciones satíricas, científicas, literarias y religiosas, también vieron la luz otras destinadas a públicos específicos, ya sean los habitantes de la campaña, las mujeres, los sectores populares o los inmigrantes italianos, españoles y franceses.

3 Diferentes abordajes sobre la opinión pública en el Río de la Plata durante el siglo XIX en Goldman (2008); Molina (2009); Myers (2003); Palti (2009).

4 La voz "diarismo" era utilizada en Hispanoamérica para hacer referencia a la prensa y, en particular, a la de carácter político (Wasserman 2009b). 